\title{
Antioxidant and anti-inflammatory mechanisms of astaxanthin in cardiovascular diseases
}

Carolina Parga Martins Pereira ${ }^{1}$

Ana Carolina Remondi Souza ${ }^{1}$

Andrea Rodrigues Vasconcelos ${ }^{2}$

Pietra Sacramento Prado ${ }^{1}$

José João Name ${ }^{1 *}$

${ }^{1}$ Kilyos Assessoria, Cursos e Palestras, São Paulo, SP - Brazil

${ }^{2}$ Department of Pharmacology, Institute of Biomedical Sciences, University of São Paulo, São Paulo/SP, Brazil.

*Corresponding author: Avenida Paulista, 777 - conjunto 11, Bela Vista, São Paulo, SP - Brazil - Zip Code: $01311-100$

Phone: +55 11 2925-6035

e-mail address: namepucsp@gmail.com 


\begin{abstract}
Cardiovascular disease is the most common cause of death. Oxidative stress and inflammation are pathophysiological processes involved in the development of cardiovascular diseases, so antiinflammatory and antioxidant agents that modulate redox balance have become the targets of research to evaluate their molecular mechanisms and therapeutic properties. Astaxanthin, a carotenoid of the xanthophyll group, has potent antioxidant effects due to its molecular structure and its arrangement in the plasma membrane, factors that favor the neutralization of reactive oxygen and nitrogen species. This carotenoid also stands out for its anti-inflammatory activity, possibly interrelated with its antioxidant effect, as well as for its modulation of lipid and glucose metabolism. Considering the potential positive effects of astaxanthin on cardiovascular health evidenced by preclinical and clinical studies, this paper describes the molecular and cellular mechanisms related to the antioxidant and anti-inflammatory properties of this carotenoid in cardiovascular diseases, especially atherosclerosis.
\end{abstract}

Keywords: astaxanthin, cardiovascular disease, atherosclerosis, inflammation, oxidative stress, carotenoids, antioxidant 


\section{Introduction}

According to data from the World Health Organization, cardiovascular diseases accounted for $31 \%$ of all causes of death in 2016 , and they are considered the leading cause of mortality worldwide [1]. One of the risk factors for cardiovascular diseases is metabolic syndrome, a multifactorial complication that includes variables such as obesity, dyslipidemia, hypertension, and glucose metabolism dysfunctions [2]. Evidence connects these variables to increased oxidative stress, and mitochondrial dysfunction, activation of enzymes that produce reactive oxygen and nitrogen species (RONS), and impairment of the activity of antioxidant systems are the main triggering mechanisms [24].

Because oxidative stress and inflammation are interrelated and contribute to the initial events of cardiovascular diseases, antioxidants that modulate redox balance, such as astaxanthin, can be considered important regulators of inflammatory responses [5] and have become the focus of research to evaluate whether and how they prevent these diseases. Astaxanthin is closely linked to other wellknown carotenoids, such as beta-carotene, lutein, and zeaxanthin, sharing various of the physiological and metabolic functions attributed to these compounds [6]. The two oxygenated groups, hydroxyl $(\mathrm{OH})$ and carbonyl $(\mathrm{C}=\mathrm{O})$, in each of its ionone rings explains some of its unique characteristics, such as its more potent antioxidant activity and polar configuration when compared to other carotenoids [6-8]. In addition to its antioxidant action, astaxanthin has anti-inflammatory properties and the ability to modulate lipid and glucose metabolism [6, 7, 9], which promote significant benefits in the cardiovascular system, preventing disorders such as atherosclerosis, arterial hypertension, and dyslipidemia [10-20]. Given the extensive evidence supporting its health-promoting properties and safety, astaxanthin was approved as a nutraceutical by the United States Food and Drug Administration in 1999 [21].

Considering the safety of using astaxanthin as a nutraceutical and the scientific evidence of its beneficial effects on cardiovascular physiology, this review describes the molecular and cellular mechanisms involved in the antioxidant and anti-inflammatory action of astaxanthin in the prevention of cardiovascular diseases.

\section{Mechanisms of action of astaxanthin}

\section{Antioxidant effect}

Cell membrane systems are particularly vulnerable to RONS attacks due to their content of polyunsaturated fatty acids (PUFAs) and their metabolic activities, which endogenously generate other oxidizing metabolites [22]. 
Astaxanthin provides cell membranes with protection against RONS and oxidative damage. Given its chemical structure, its polar groups overlap the polar regions of the cell membrane, while the central nonpolar region of the molecule fits into the inner nonpolar region of the membrane. Thus, this carotenoid can take on a transmembrane alignment in biological membranes, allowing it to help maintain the membrane structure, decrease membrane fluidity, and act as an antioxidant [17, 23, 24].

Astaxanthin scavenges RONS and other reactive species (sulfur and carbon) directly, both by donating electrons and by bonding with the free radical to form a nonreactive product [25]. In addition, the presence of a series of conjugated bonds in the central nonpolar region of astaxanthin gives the molecule another antioxidant dimension, i.e., the ability to remove free radicals (high-energy electrons) from the cell interior by transporting them along its own carbon chain, as if it were a "lightning rod" for these electrons, so that these are neutralized by other antioxidants located outside the cell membrane, such as vitamin C [25].

The increased susceptibility of membrane lipids and low-density lipoprotein (LDL) to oxidation may trigger the formation of thrombi and the development of atherosclerosis [5]. One of the reactive species that induces lipid peroxidation and LDL oxidation is peroxynitrite $\left(\mathrm{ONOO}^{-}\right)[50,51]$, which when neutralized by astaxanthin forms 15-nitroastaxanthin, a compound that also has important antioxidant action [52].

The LDL oxidation time in the presence of astaxanthin has been analyzed in vitro and ex vivo. In the in vitro assays, astaxanthin prolonged LDL oxidation in a dose-dependent manner, in addition to being more effective at this function than lutein and $\alpha$-tocopherol. In turn, the blood samples of individuals who were supplemented daily with $1.8 \mathrm{mg}, 3.6 \mathrm{mg}, 14.4 \mathrm{mg}$, or $21.6 \mathrm{mg}$ of astaxanthin for 14 days evidenced a significant delay in LDL oxidation when compared to samples taken before supplementation, the greatest effect being obtained with the dose of $14.4 \mathrm{mg}$ (oxidation time increased by $5.0,26.2,42.3$, and $30.7 \%$ under the doses of $1.8,3.6,14.4 \mathrm{n}$ and $21.6 \mathrm{mg}$, respectively) (Table 1 ) [10]. The differences in oxidation time exhibited by the different groups were not addressed by the authors. Thus, this study showed that the intake of astaxanthin prevents LDL oxidation, one of the factors involved in the process of atherosclerosis.

LDL oxidation is also associated with the development of endothelial dysfunction in patients with diabetes mellitus, which raises the risk of cardiovascular complications [26]. Endothelial dysfunction consists of impaired vessel relaxation dependent on endothelial factors, such as the production of nitric oxide (NO) by endothelial nitric oxide synthase (eNOS) [27]. One of the pathways responsible for this type of dysfunction is the binding of oxidized LDL with its endothelial receptor, lectin-like ox-LDL receptor 1 (LOX-1), thus favoring oxidative stress, which leads to increased lipid peroxidation and eNOS inactivation [28]. Supplementation with $10 \mathrm{mg} / \mathrm{kg}$ astaxanthin for 42 days in a diabetic rat model increased artery relaxation by significantly lowering oxidized LDL, LOX-1 receptor, and lipid peroxidation in the aorta, in addition to increasing eNOS, demonstrating that astaxanthin may have therapeutic potential for the treatment of endothelial dysfunction in diabetic patients [29]. 
Erythrocytes have a large amount of PUFAs and high concentrations of oxygen and ferrous ions $\left(\mathrm{Fe}^{2+}\right)$, which makes these cells more susceptible to oxidative changes in the lipid bilayer, leading to compromised cell stability, oxygen transport, and blood rheology [30]. The oxidation of erythrocytes is associated with both the formation of atheromas and the occurrence of intraplate hemorrhage during the development of atherosclerosis [31]. Regarding lipid peroxidation in erythrocytes, daily supplementation with $6 \mathrm{mg}$ or $12 \mathrm{mg}$ of astaxanthin for 12 weeks in healthy individuals showed that this carotenoid is incorporated and distributed into these blood cells. When incorporated into erythrocytes, astaxanthin exhibited antioxidant effects in the cell membrane by significantly reducing the levels of phospholipid hydroperoxides (PLOOH), which are the primary products of phospholipid oxidation ( $14.9 \mathrm{pmol} / \mathrm{ml}$ for the placebo group and 8.0 and $9.7 \mathrm{pmol} / \mathrm{ml}$ for the 6 and $12 \mathrm{mg}$ astaxanthin groups, respectively). In that study, the two doses of astaxanthin used had similar effects when compared to placebo, suggesting that the intake of $6 \mathrm{mg}$ of this carotenoid is enough to inhibit oxidative stress in erythrocytes (Table 1) [12]. A significant reduction in oxidative damage by lipid peroxidation was also observed, as the plasma levels of 12- and 15-hydroxy fatty acids ( $p=0.048$ and $p=0.047$, respectively) decreased after three months of supplementation with $8 \mathrm{mg}$ of astaxanthin in healthy men (Table 1) [13].

Blood rheology is important to cardiovascular homeostasis. Astaxanthin has reduced blood transit time in a hypertensive rat model [32] and in humans [18]. In the latter study, individuals supplemented with $6 \mathrm{mg}$ of astaxanthin for ten days had significantly faster blood transit time than they did before supplementation and than the placebo group ( $47.6 \pm 4.2 \mathrm{~s}$ vs. $54.2 \pm 6.7 \mathrm{~s}$ for the treated and placebo groups, respectively; $p<0.05$ ) (Table 1) [18]. One hypothesis for the improvement of blood rheology by astaxanthin is its antioxidant effect in the intra- and extracellular environment and the consequent increase in the flexibility of the erythrocyte membrane, conferred by the structural arrangement of astaxanthin in the membrane.

Other factors that affect the blood flow velocity, such as plasma viscosity and vasodilation, influence peripheral vascular resistance and may contribute to hypertension and its main cardiac complication, myocardial hypertrophy [33]. Studies of spontaneously hypertensive rats (SHR) reported that astaxanthin supplementation significantly reduced systolic pressure and induced significant histological changes in the aorta associated with decreased vascular stiffness and blood pressure [3436]. This response was caused by increased endothelial cell-dependent vasodilation due to the greater bioavailability of NO, as well as the remodeling of the arteries. The increase in NO was caused by the reduced production of superoxide anion radicals released by NADPH oxidase, one of the antioxidant effects of astaxanthin $[34,35]$. Chen et al. (2020) showed that this carotenoid also acted in the remodeling of the smooth muscle cells of the vessels, reducing their proliferation and the damage caused by oxidative stress. Astaxanthin lowered RONS by increasing the activity of antioxidant enzymes and regulating mitochondrial dynamics, mitophagy, and mitochondrial biogenesis, which are important events for the maintenance of mitochondrial and cellular metabolism [36]. 
The high bioavailability of NO due to lower oxidative stress promoted by astaxanthin was also associated with anti-thrombogenic effects. In a stroke-prone SHR model, astaxanthin significantly downregulated the oxidative stress marker 8-hydroxy-2'-deoxyguanosine (8-OHdG) in the urine, lowered systolic blood pressure, and lessened thrombogenesis in the cerebral veins. The observed antithrombogenic effect may have been due to vasodilation and inhibition of platelet aggregation caused by an increased bioavailability of NO [37]. In a murine model of thrombosis treated with astaxanthin in the form of the CDX-085 prodrug, an increase of approximately $20 \%$ in the blood flow of the carotid artery was observed before the occurrence of endothelial dysfunction, as was a delay in the formation of occlusive thrombi. These results were due to the increase in NO and the decrease in ONOO- The authors suggested that the increase in blood flow was due to vasodilation caused by increased release of NO by endothelial cells and reduced platelet activation triggered by the antioxidant effect [38].

Some of the vascular benefits promoted by the antioxidant effect of astaxanthin were reported in an open study of 20 postmenopausal women who had a high rate of oxidative stress [14]. After eight weeks of supplementation with $12 \mathrm{mg}$ of astaxanthin, there was a significant reduction of $4.64 \%$ and $6.93 \%$ in the systolic and diastolic pressure values, respectively, possibly resulting from the reduction in the vascular tone due to the action of the carotenoid in the endothelium. Reduced vascular resistance in the lower limbs (3.7\% increase in the ankle-brachial pressure index), a $4.58 \%$ increase in antioxidant capacity, and improvement of some physical and mental symptoms, such as tired eye sensation and difficulty sleeping, were also observed [14].

In addition to the protective action of astaxanthin in the lipid oxidation process, this carotenoid influences the activity of antioxidant enzymes involved in lipid metabolism, such as thioredoxin reductase (TrxR) and paraoxonase-1. TrxR is an antioxidant enzyme involved in the reduction of thioredoxin, lipid hydroperoxides, and hydrogen peroxide [39]. One study showed that thioredoxin in its oxidized form was associated with the degree of severity of chronic heart failure and with the oxidative stress resulting from this pathology [40]. Paraoxonase-1 is an enzyme that binds to serum high-density lipoprotein (HDL) and is responsible for protecting both LDL and HDL from oxidation processes, as well as for breaking down oxidized lipids [41]. The effect of astaxanthin on these two enzymes was evaluated in rabbits fed a diet rich in cholesterol [42]. The authors found that astaxanthin (100 and $500 \mathrm{mg} / 100 \mathrm{~g}$ of feed) reduced the amount of oxidized protein, possibly due to changes in the activities of TrxR and paraoxonase-1, but the in vitro evaluation showed only the direct action of this molecule on TrxR [42].

Once again demonstrating the antioxidant effects of astaxanthin, Choi et al. [11, 16] conducted two randomized and double-blind clinical studies with overweight or obese individuals (Table 1). In one study, volunteers supplemented with $5 \mathrm{mg}$ and $20 \mathrm{mg}$ of astaxanthin for three weeks showed lower oxidative stress biomarkers associated with lipid peroxidation than before treatment, with $34.6 \%$ and $35.2 \%$ reductions in malondialdehyde (MDA) levels and 64.9\% and 64.7\% in the isoprostane (ISP) levels, respectively. An increase in the activity of the antioxidant defense system was also observed, 
with $193 \%$ and $194 \%$ increases in superoxide dismutase (SOD) and $121 \%$ and $125 \%$ in total antioxidant capacity at the doses of $5 \mathrm{mg}$ and $20 \mathrm{mg}$, respectively, compared to the data before treatment [16]. In that study, no significant differences were observed between the results obtained under the two doses, showing that the clinical effects of this carotenoid are not proportional to the dose. Later, the same authors analyzed lipid profile, oxidative stress, and antioxidant system parameters [11]. After 12 weeks of supplementation with $20 \mathrm{mg}$ of astaxanthin, the same results were observed in oxidative stress and the antioxidant system as in the previous study. Regarding the lipid profile, there was a significant reduction of $10.4 \%$ in the LDL concentration, $7.59 \%$ in ApoB, and $8.22 \%$ in the ApoA1/ApoB ratio (considered an index of the risk of heart attack) compared to the placebo group values [11]. Therefore, these studies show that astaxanthin reduces oxidative stress and modulates the lipid profile in overweight and obese individuals, mitigating the risk of developing cardiovascular diseases.

Astaxanthin also has potent detoxifying and antioxidant effects in smokers [15]. The free radicals induced by smoking have been strongly associated with increased oxidative stress, contributing to the increased susceptibility of smokers to the pathogenesis of cardiovascular diseases. This group of individuals requires a higher daily intake of antioxidants than nonsmokers to reduce the consequences of prolonged exposure to toxins present in cigarettes. After three weeks, supplementation with different doses of astaxanthin (5 mg, $20 \mathrm{mg}$, and $40 \mathrm{mg}$ ) in active smokers prevented oxidative damage by suppressing lipid peroxidation and stimulating the activity of the antioxidant system (Table 1) [15]. This effect was confirmed by the significant reductions in serum MDA and ISP and increased SOD and total antioxidant capacity in the three astaxanthin groups compared to the indices before treatment [15]. The authors also observed that the serum concentration of astaxanthin in the groups treated with $20 \mathrm{mg}$ and $40 \mathrm{mg}$ was similar, showing that there was saturation of its absorption and that smaller doses, such as $5 \mathrm{mg}$, may have the necessary antioxidant effect for these individuals. However, placebo-controlled studies with larger groups and longer interventions may help determine the best dosage for smokers.

Several preclinical studies have shown that astaxanthin also exerts an indirect antioxidant effect by activating transcription factor nuclear factor erythroid 2-related factor 2 (Nrf2), increasing the expression of its antioxidant target genes, such as phase II biotransformation enzymes [43-49]. A study with a model of coronary microembolization in rats showed that supplementation with astaxanthin drastically attenuated the induction of cardiac dysfunction, myocardial infarction, and cardiomyocyte apoptosis, which was associated with the suppression of oxidative stress via activation of $\mathrm{Nrf} / \mathrm{HO}-1$ signaling [44].

Thus, astaxanthin can accumulate in the blood plasma and, by its antioxidant action, help reduce the levels of RONS responsible for LDL oxidation and lipid peroxidation; increase the bioavailability of NO, enabling its vasodilator and anti-thrombogenic effects; increase the activity of antioxidant enzymes; and ensure the stability of blood rheological properties, thus avoiding the loss of erythrocyte flexibility and the increase in plasma viscosity, factors that influence the blood flow 
velocity. These actions of astaxanthin against early events of atherosclerotic plaque formation and arterial dysfunction can slow the progression of cardiovascular diseases (Figure 1).
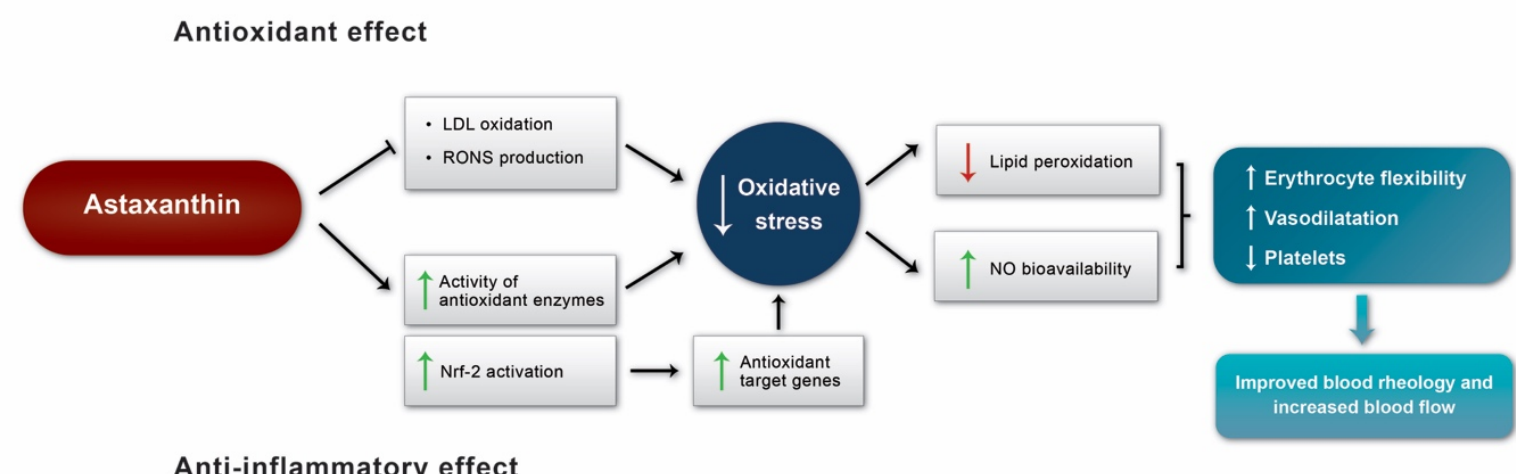

Anti-inflammatory effect

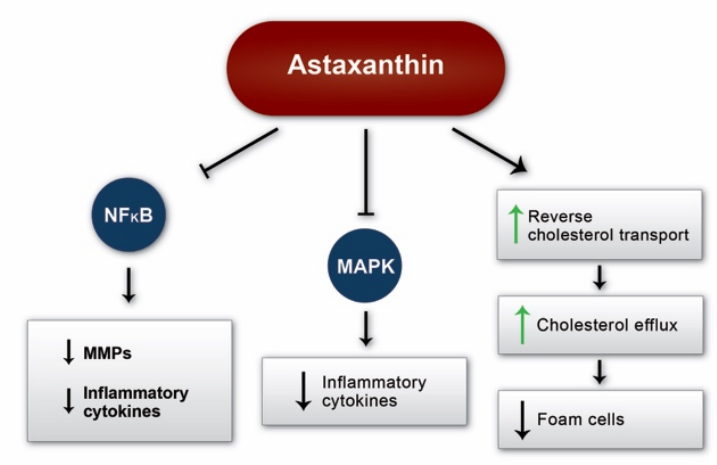

Figure 1. Scheme of the antioxidant and anti-inflammatory mechanisms of astaxanthin in cardiovascular diseases.

\section{Anti-inflammatory effect}

Inflammation plays an important role in the development of cardiovascular diseases and other comorbidities, such as hypertension, hypercholesterolemia, type 2 diabetes, chronic kidney disease, and obesity [50]. Astaxanthin exerts a marked anti-inflammatory effect, which may be interrelated with its antioxidant effect and contributes to physiological changes that benefit cardiovascular function (Figure 1) [50-55].

Atherosclerosis is a degenerative and chronic disease that affects large- and medium-caliber arteries. Atherogenesis, the initial phase of the atherosclerotic process, is characterized by the accumulation of LDL in the subendothelial layer of the vascular wall, which is responsible for inflammation mediated by the innate and adaptive immune responses [56]. The anti-inflammatory effects promoted by astaxanthin are evidenced in its role in atherosclerosis prevention, as will be detailed below. 
The epitopes generated from enzymatic or nonenzymatic oxidation of LDL are the main damage-associated molecular patterns (DAMPs) recognized by macrophages and are responsible for the onset of the inflammatory cascade, with the release of cytokines and chemokines that recruit more resident vascular macrophages and monocytes from the blood. Macrophages bind to oxidized LDL via scavenger receptors, such as SR-A, SR-B2 (CD36), and LOX-1 [56]. The expression of these receptors is controlled by nuclear factor- $\kappa \mathrm{B}(\mathrm{NF}-\kappa \mathrm{B})$, the main mediator of the inflammatory response, which is activated by pattern recognition receptors (PRRs) and pro-inflammatory cytokines [57]. In inflammatory states, macrophages produce excessive amounts of pro-inflammatory mediators, such as cytokines, chemokines, NO, cyclooxygenase-2 (COX-2), and matrix metalloproteinases (MMPs). MMPs are responsible for the degradation of most extracellular matrix proteins and mediate the tissue remodeling associated with atherosclerosis [5].

In vitro and in vivo studies have evaluated the effect of astaxanthin on the formation of atherosclerotic plaques [51-55, 58-79]. Supplementation with $10 \mu \mathrm{M}$ astaxanthin significantly reduced the expression of the SR-A and CD36 scavenger receptors in the THP-1 macrophage line and reduced the total activity of MMPs, represented by reduced protein expression of MMP-9 and MMP-2 and of the mRNA levels of five MMPs [59]. Astaxanthin at this concentration also reduced the gene expression of pro-inflammatory markers such as interleukin (IL)-1 $\beta$, IL-6, tumor necrosis factor (TNF)- $\alpha$, inducible nitric oxide synthase (iNOS), and COX-2 [59]. These results corroborate other studies that indicated that astaxanthin reduces the expression of pro-inflammatory mediators in macrophages [59$62]$ and in other cell types, such as microglia, endothelial vascular cells, and human neutrophils [63$66]$.

The significant decreases in MMPs and proinflammatory cytokines may have resulted from the suppression of the NF- $\mathrm{BB}$ transcription factor by astaxanthin $[51-55,59,61,65,67,68]$. NF- $\kappa \mathrm{B}$ is frequently activated at inflammation sites associated with various pathologies, especially cardiovascular diseases, in which the increased expression of its pro-inflammatory target genes plays a critical role in the etiology of these diseases [69]. The inflammatory pathway of NF- $\mathrm{kB}$ is, at least in part, regulated by oxidative stress [69]. Astaxanthin inhibits the activity of IאB kinase (IKK), a complex responsible

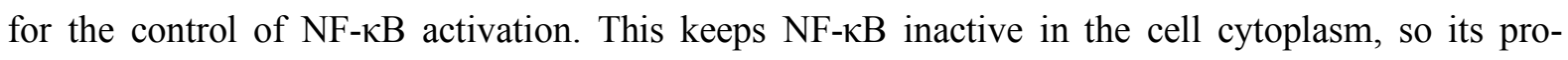
inflammatory target genes, such as TNF- $\alpha$, IL-1 $\beta$, and iNOS, are downregulated [61].

Cholesterol uptake is balanced by the transfer of this molecule from macrophages to free apolipoproteins A1 or to HDL, the latter being responsible for the reverse cholesterol transport process. When cholesterol uptake exceeds cholesterol efflux in macrophages, lipid droplets accumulate in the cytoplasm, forming foam cells, the main markers of atherosclerosis (Figure 2) [56]. The progression of cholesterol accumulation can lead to its precipitation in the form of crystals, which activate the inflammasome, leading to cell death by apoptosis or necrosis [80]. The atherosclerotic plaque is 
separated from the bloodstream by a fibrous layer, which upon rupture initiates intraluminal thrombosis, the initial event of stroke and other coronary syndromes [56].

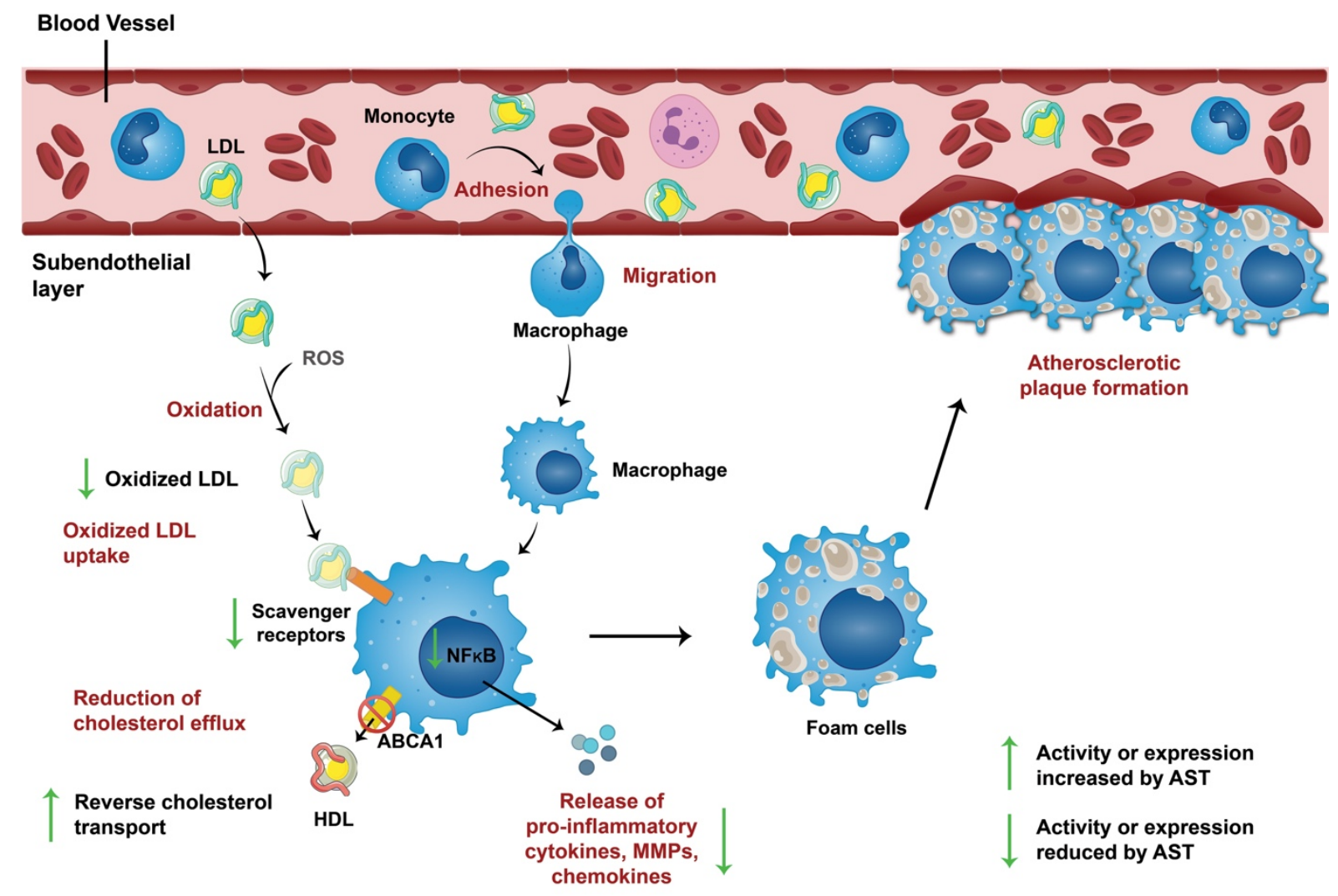

Figure 2. Mechanism of atherosclerotic plaque formation in the subendothelial layer of the vascular wall and the action of astaxanthin.

AST $=$ astaxanthin (adapted from [5]).

Reverse cholesterol transport consists in HDL removing excess cholesterol from peripheral tissues and transporting it to the liver, where it is degraded by bile juice and excreted in the feces, thus preventing the accumulation of cholesterol in macrophages [76]. Both the liver and intestine synthesize apolipoprotein A-I (apoA-I) and apoA-II in plasma, which incorporate free cholesterol and phospholipids through the ATP-binding cassette A1 (ABCA1) hepatic transporter, originating from nascent HDL. In peripheral tissues, nascent HDL molecules recruit free cholesterol from foam cells via the macrophage ABCA1 transporter [77]. It is noteworthy that this reverse cholesterol transport was also observed in the lymphatic system, which is responsible for much of the removal of cholesterol from different tissues [76]. Finally, mature HDL can transport cholesterol directly to the liver via the SR-B1 scavenger receptor or can transfer cholesteryl esters to (very) low-density lipoproteins [(V)LDL] through the CETP (cholesteryl ester transfer protein) [78]. These lipoproteins are absorbed in the liver by their specific receptors, which is probably the predominant pathway in humans. Once in the liver, cholesterol is secreted into the bile via the ABCG5 and ABCG8 transporters. Some of these molecules 
can be reabsorbed by the intestine and reach the bloodstream again, while the rest is excreted in the feces [77].

In atherosclerosis, apolipoproteins are oxidized by the enzyme myeloperoxidase, which is expressed in macrophages during the inflammatory process, compromising cholesterol efflux via ABCA1 [78]. In individuals with heart disease, elevated levels of apoA-I modified by myeloperoxidase were identified, and their HDL molecules were dysfunctional in performing reverse cholesterol transport. In addition, an association was observed between increased cholesterol efflux via ABCA1 and reduced risk of cardiovascular diseases (OR: 0.30; 95\% CI, 0.14-0.66; $<<0.003$ ) [79]. Thus, the oxidation of apolipoproteins by macrophage myeloperoxidase is a determining factor in HDL dysfunction in cholesterol transport and therefore in the risk of cardiovascular diseases.

The effects of astaxanthin on reverse cholesterol transport have been demonstrated in vivo. In wild-type and $\mathrm{ApoE}^{-/}$mice, astaxanthin increased cholesterol efflux from peripheral tissues to the liver and its subsequent excretion in feces [58]. In addition, in the $\mathrm{ApoE}^{-/}$model, this carotenoid promoted a significant decline in plasma total cholesterol, triglycerides, and non-HDL cholesterol and reduced the atherosclerotic plaque area of the aortic sinus and the cholesterol concentration in the aorta compared to controls. Thus, astaxanthin exerts anti-atherosclerotic effects by increasing the reverse cholesterol transport pathway, but the molecular mechanisms of this action are still unknown [58].

In addition to acting in reverse cholesterol transport, astaxanthin acts in some lipid metabolism steps, a finding corroborated by a randomized, placebo-controlled clinical study of 61 adult individuals with moderate hyperlipidemia [20] (Table 1). In that study, daily supplementation with 6,12 , or $18 \mathrm{mg}$ of astaxanthin for 12 weeks promoted an improvement in the lipid profile of the patients. Triglycerides were reduced $25.2 \%$ and $23.8 \%(\mathrm{p}<0.05)$ by doses of 12 and $18 \mathrm{mg}$, respectively. HDL was increased $10.6 \%(\mathrm{p}<0.05)$ and $15.4 \%(\mathrm{p}<0.01)$ by doses of 6 and $12 \mathrm{mg}$, respectively. The doses of 12 and $18 \mathrm{mg}$ also significantly increased serum adiponectin ( $p<0.01$ and $p<0.05$, respectively), a protein secreted by adipocytes with important functions in the cardiovascular and endocrine systems associated with its anti-inflammatory, atheroprotective, and insulin-sensitizing actions [20].

Inflammation is also involved in the pathophysiology of metabolic syndrome, a multifactorial disorder associated with glucose and lipid metabolism disorders. This disease has risk factors that are also strongly associated with the development of cardiovascular complications, including type 2 diabetes, dyslipidemia, hypertension, and abdominal fat deposition [81]. In this context, astaxanthin has been promising in the improvement of glucose and lipid metabolism in a randomized, placebocontrolled clinical study with 43 diabetic patients aged between 46 and 62 years [19] (Table 1). In agreement with a previous clinical study [20], supplementation with astaxanthin $(8 \mathrm{mg} /$ day for 8 weeks) significantly increased serum adiponectin $(47 \pm 14 \mu \mathrm{g} / \mathrm{mL}$ vs. $45 \pm 13 \mu \mathrm{g} / \mathrm{mL}$ and $36 \pm 15 \mu \mathrm{g} / \mathrm{mL}$ compared to placebo and baseline, respectively; $p<0.05$ ) and improved the lipid profile of patients, as shown by the reductions in triglycerides $(128 \pm 52 \mathrm{mg} / \mathrm{dL}$ vs. $150 \pm 85 \mathrm{mg} / \mathrm{dL}$ and $156 \pm 90 \mathrm{mg} / \mathrm{dL}$ compared to placebo and baseline, respectively; $\mathrm{p}<0.05)$ and VLDL $(27 \pm 16 \mathrm{mg} / \mathrm{dL}$ vs. $31 \pm 16 \mathrm{mg} / \mathrm{dL}$ 
compared to placebo; $\mathrm{p}<0.05)$. Furthermore, astaxanthin marginally reduced fasting glucose $(8.3 \pm 2.7$ $\mathrm{mmol} / \mathrm{L}$ vs. $9.4 \pm 3.2 \mathrm{mmol} / \mathrm{L}$ compared to placebo; $\mathrm{p}=0.057)$ and significantly increased serum fructosamine $(5.8 \pm 3.8 \mu \mathrm{mol} / \mathrm{L}$ vs. $7.32 \pm 4.31 \mu \mathrm{mol} / \mathrm{L}$ and $7.36 \pm 4.2 \mu \mathrm{mol} / \mathrm{L}$ compared to placebo and baseline, respectively; $\mathrm{p}<0.05$ ), an important marker in the control of diabetes that signals the mean concentration of blood glucose. Patients supplemented with astaxanthin also showed lower visceral fat deposition $(11.2 \pm 3.4 \%$ vs. $11.85 \pm 3.8 \%$ compared to placebo; $\mathrm{p}<0.05)$ and systolic blood pressure $(132 \pm 18 \mathrm{mmHg}$ vs. $133 \pm 19 \mathrm{mmHg}$ and $143 \pm 27 \mathrm{mmHg}$ compared to placebo and baseline, respectively; $\mathrm{p}<0.05)$ [19].

Disorders characterized by ischemia/reperfusion, including myocardial infarction, stroke, and peripheral vascular disease, are among the most frequent causes of morbidity and mortality worldwide [81]. Ischemia/reperfusion is a complex inflammatory process associated with high levels of oxidative stress in the affected tissue [82]. In rodents with hepatic lesions induced by ischemia/reperfusion, astaxanthin not only reduced oxidative stress and histopathological damage [83, 84] but also exerted a significant anti-inflammatory effect, attenuating the release of inflammatory cytokines through the mitogen-activated protein kinase (MAPK) pathway [84, 85]. Furthermore, astaxanthin promoted an anti-inflammatory and antioxidant effect in the context of myocardial injury due to ischemia/reperfusion in rabbits by significantly reducing the activation of the complement system associated with the reduced deposition of C-reactive protein and the membrane attack complex in the injured area of the myocardium [86].

In mice with nonalcoholic steatohepatitis (NASH) induced by a hyperlipidic diet, supplementation with astaxanthin $(0.02 \%$ in the diet, approximately $20 \mathrm{mg} / \mathrm{kg}$ body weight) significantly improved several liver parameters: It reduced liver inflammation, decreased the proportion of pro-inflammatory M1-type macrophages, reduced stellate cells activation, and attenuated liver fibrosis, the accumulation and peroxidation of hepatic lipids, and insulin resistance [87]. Additionally, astaxanthin was more effective in preventing and treating NASH and improving liver inflammation and fibrosis than vitamin E (standard NASH treatment). The same study also corroborated the potential of astaxanthin to improve NASH in 12 individuals supplemented with this carotenoid ( $12 \mathrm{mg} /$ day; control: placebo) for 24 weeks [87].

The anti-inflammatory and antioxidant effects of astaxanthin were also confirmed by a randomized clinical trial in 42 healthy young women supplemented with placebo or astaxanthin at 2 or $8 \mathrm{mg} /$ day [17] (Table 1). In comparison to placebo, after eight weeks of treatment, the $2 \mathrm{mg}$ dose significantly lowered the plasma inflammatory marker C-reactive protein (unspecified values; $\mathrm{p}<0.05$ ). Astaxanthin improved the immune responses of the participants, as evidenced by the increased cytotoxic activity of natural killer cells ( $8 \mathrm{mg}$ dose, $67.9 \pm 3.0 \%$ vs. $57.8 \pm 2.7 \%$ lysis; $\mathrm{p}<0.05$ ), levels of $\mathrm{T}$ and B lymphocytes ( $2 \mathrm{mg}$ dose, $75.7 \pm 1.6 \%$ vs. $70.6 \pm 1.5 \%$ and $13.1 \pm 0.5 \%$ vs. $10.7 \pm 0.5 \%$, respectively; $\mathrm{p}<0.05$ ), and production of interferon- $\gamma$ and IL-6 (dose of $8 \mathrm{mg}, 9.55 \mathrm{pg} / \mathrm{mL}$ vs. 4.68 $\mathrm{pg} / \mathrm{mL}$ and $25.2 \mathrm{pg} / \mathrm{mL}$ vs. $13.6 \mathrm{pg} / \mathrm{mL}$, respectively; $\mathrm{p}<0.05$ ). Finally, starting at 4 weeks, both doses 
drastically reduced plasma $8-\mathrm{OHdG}$ (unspecified values; $\mathrm{p}<0.01$ ), a biomarker of oxidative DNA damage [17].

In summary, inflammation plays an essential role in the pathophysiology of cardiovascular diseases and their risk factors, while astaxanthin has therapeutic effects stemming from its antiinflammatory action. The mechanism of action of this carotenoid involves the inhibition of the NF- $\mathrm{BB}$ and MAPK signaling pathways, which reduces the inflammatory process and stimulates reverse cholesterol transport, thereby attenuating the formation of foam cells (Figure 1).

\section{Clinical evidence of the prevention of cardiovascular diseases by astaxanthin}

Potential positive effects of oral astaxanthin supplementation on cardiovascular physiology were evidenced in eleven clinical studies, summarized in Table 1. Of these eleven studies, six were randomized placebo-controlled studies [11-13, 17, 19, 20], one was single-blinded [18], two were open-label $[10,14]$, and two were randomized but lacked a placebo group [15, 16]. Six studies evaluated the metabolic and oxidative changes promoted by astaxanthin in healthy individuals, while five of them investigated individuals who had one dimension of metabolic syndrome, such as obesity, dyslipidemia, and type 2 diabetes. In addition, the dose of astaxanthin ranged between $1.8 \mathrm{mg}$ and 40 $\mathrm{mg}$, and the duration of supplementation varied between 10 days and 12 weeks, reflecting a wide variety of these two parameters. Despite encompassing a small population with a total of 417 individuals, their results show that the action of astaxanthin in promoting cardiovascular health is mainly due to its antioxidant and anti-inflammatory effects, its ability to modulate lipid and glucose metabolism, and its role in the maintenance of blood rheology. 
Table 1. Clinical studies that have shown the potential positive effects of oral astaxanthin supplementation on cardiovascular physiology.

\begin{tabular}{|c|c|c|c|c|c|}
\hline Study type & Individuals & $\begin{array}{l}\text { Intervention (number of } \\
\text { individuals per group) }\end{array}$ & $\begin{array}{c}\text { Mechanism of } \\
\text { action evaluated }\end{array}$ & Main findings & Reference \\
\hline Open-label & $\begin{array}{l}24 \text { healthy volunteers } \\
\text { (mean } 28.2 \pm 7.8 \text { years) }\end{array}$ & $\begin{array}{l}\text { Control }(\mathrm{n}=6)^{\mathrm{a}} ; \\
\text { AST } 1.8 \mathrm{mg} / \text { day }(\mathrm{n}=5) ; \\
\text { AST } 3.6 \mathrm{mg} / \text { day }(\mathrm{n}=5) ; \\
\text { AST } 14.4 \mathrm{mg} / \text { day }(\mathrm{n}=3) ; \\
\text { AST } 21.6 \mathrm{mg} / \text { day }(\mathrm{n}=5) \\
14 \text { days }\end{array}$ & Antioxidant effect & Delayed LDL oxidation time & {$[10]$} \\
\hline $\begin{array}{l}\text { Randomized, } \\
\text { double-blind, } \\
\text { placebo- } \\
\text { controlled }\end{array}$ & $\begin{array}{l}27 \text { overweight and } \\
\text { obese adults (BMI> } 25 \\
\left.\mathrm{~kg} / \mathrm{m}^{2}\right)(20-55 \text { years })\end{array}$ & $\begin{array}{l}\text { Placebo }(\mathrm{n}=13) \\
\text { AST } 20 \text { mg/day }(\mathrm{n}=14) \\
12 \text { weeks }\end{array}$ & Antioxidant effect & $\begin{array}{l}\text { Reduced LDL, ApoB, and ApoA1/ApoB ratio } \\
\text { relative to baseline; } \\
\text { Increased TAC and SOD compared to baseline; } \\
\text { Reduced lipid peroxidation biomarkers (MDA and } \\
\text { ISP) compared to baseline. }\end{array}$ & {$[11]$} \\
\hline $\begin{array}{l}\text { Randomized, } \\
\text { double-blind, } \\
\text { placebo- } \\
\text { controlled }\end{array}$ & $\begin{array}{l}30 \text { healthy individuals } \\
\text { (50-69 years) }\end{array}$ & $\begin{array}{l}\text { Placebo }(\mathrm{n}=10) \\
\text { AST } 6 \mathrm{mg} / \text { day }(\mathrm{n}=10) \\
\text { AST } 12 \mathrm{mg} / \text { day }(\mathrm{n}=10) \\
12 \text { weeks }\end{array}$ & Antioxidant effect & $\begin{array}{l}\text { Reduced phospholipid hydroperoxide levels in } \\
\text { erythrocytes }\end{array}$ & [12] \\
\hline $\begin{array}{l}\text { Randomized, } \\
\text { double-blind, } \\
\text { placebo- } \\
\text { controlled }\end{array}$ & $\begin{array}{l}39 \text { healthy men }(19-33 \\
\text { years) }\end{array}$ & $\begin{array}{l}\text { Placebo }(\mathrm{n}=19) ; \\
\text { AST } 8 \mathrm{mg} / \text { day }(\mathrm{n}=20) \\
3 \text { months }\end{array}$ & Antioxidant effect & $\begin{array}{l}\text { Reduced plasma lipid peroxidation, especially } 12- \\
\text { hydroxy and } 15 \text {-hydroxy fatty acids }\end{array}$ & [13] \\
\hline $\begin{array}{l}\text { Open-label, } \\
\text { uncontrolled } \\
\text { study }\end{array}$ & $\begin{array}{l}20 \text { healthy } \\
\text { postmenopausal women } \\
\text { with high oxidative } \\
\text { stress levels (mean } 55.7 \\
\pm 4.8 \text { years) }\end{array}$ & $\begin{array}{l}\text { AST } 12 \mathrm{mg} / \text { day }(\mathrm{n}=20) \\
8 \text { weeks }\end{array}$ & Antioxidant effect & $\begin{array}{l}\text { Lowered blood pressure; } \\
\text { Increased antioxidant capacity; } \\
\text { Reduced vascular resistance in lower limbs and } \\
\text { serum adiponectin }\end{array}$ & [14] \\
\hline Randomized & $\begin{array}{l}39 \text { smokers ( } \geq 20 \\
\text { cigarettes per day) and }\end{array}$ & $\begin{array}{l}\text { Control }(\mathrm{n}=39)^{\mathrm{b}} \text {; } \\
\text { AST } 5 \mathrm{mg} / \text { day }(\mathrm{n}=13) \\
\text { AST } 20 \mathrm{mg} / \text { day }(\mathrm{n}=13)\end{array}$ & Antioxidant effect & $\begin{array}{l}\text { Reduced MDA and ISP; } \\
\text { Increased SOD and TAC }\end{array}$ & [15] \\
\hline
\end{tabular}




\begin{tabular}{|c|c|c|c|c|c|}
\hline & $\begin{array}{l}39 \text { nonsmokers (21-43 } \\
\text { years) }\end{array}$ & $\begin{array}{l}\text { AST } 40 \text { mg/day }(n=13) \\
3 \text { weeks }\end{array}$ & & & \\
\hline $\begin{array}{l}\text { Randomized, } \\
\text { double-blind }\end{array}$ & $\begin{array}{l}23 \text { overweight }(25 \\
\mathrm{kg} / \mathrm{m} 2<\mathrm{BMI} \leq 29.9 \\
\mathrm{~kg} / \mathrm{m} 2) \text { and obese } \\
(\mathrm{BMI}>30 \mathrm{~kg} / \mathrm{m} 2) \\
\text { individuals (mean } 25.1 \\
\pm 3.7 \text { years) }\end{array}$ & $\begin{array}{l}\text { Control }(\mathrm{n}=10)^{\mathrm{c}} \text {; } \\
\text { AST } 5 \mathrm{mg} / \text { day }(\mathrm{n}=12) \\
\text { AST } 20 \mathrm{mg} / \text { day }(\mathrm{n}=11) \\
3 \text { weeks }\end{array}$ & Antioxidant effect & $\begin{array}{l}\text { Reduced MDA and ISP; } \\
\text { Increased SOD and TAC }\end{array}$ & [16] \\
\hline $\begin{array}{l}\text { Randomized, } \\
\text { double-blind, } \\
\text { placebo- } \\
\text { controlled }\end{array}$ & $\begin{array}{l}61 \text { healthy individuals } \\
\text { with triglyceride levels } \\
\text { between } 120-200 \mathrm{mg} / \mathrm{dl} \\
(25-60 \text { years })\end{array}$ & $\begin{array}{l}\text { Placebo }(\mathrm{n}=15) ; \\
\text { AST } 6 \mathrm{mg} / \text { day }(\mathrm{n}=15) ; \\
\text { AST } 12 \mathrm{mg} / \text { day }(\mathrm{n}=15) \\
\text { AST } 18 \mathrm{mg} / \text { day }(\mathrm{n}=16) \\
12 \text { weeks }\end{array}$ & Lipid metabolism & $\begin{array}{l}\text { Reduced triglyceride levels; } \\
\text { Increased HDL; } \\
\text { Increased adiponectin }\end{array}$ & [20] \\
\hline $\begin{array}{l}\text { Randomized, } \\
\text { double-blind, } \\
\text { placebo- } \\
\text { controlled }\end{array}$ & $\begin{array}{l}42 \text { healthy young } \\
\text { women }(20-22 \text { years })\end{array}$ & $\begin{array}{l}\text { Placebo }(\mathrm{n}=14) \text {; } \\
\text { AST } 2 \mathrm{mg} / \text { day }(\mathrm{n}=14) \text {; } \\
\text { AST } 8 \mathrm{mg} / \text { day }(\mathrm{n}=14) \\
8 \text { weeks }\end{array}$ & $\begin{array}{l}\text { Anti- } \\
\text { inflammatory and } \\
\text { antioxidant effect }\end{array}$ & $\begin{array}{l}\text { Increased total number of } \mathrm{T} \text { and } \mathrm{B} \text { lymphocytes; } \\
\text { Increased cytotoxic activity of natural killer cells; } \\
\text { Reduced the biomarkers of oxidative damage 8- } \\
\text { hydroxy-2'-deoxyguanosine and C-reactive } \\
\text { protein }\end{array}$ & [17] \\
\hline Single-blind & $\begin{array}{l}20 \text { healthy adult men } \\
(37-67 \text { years })\end{array}$ & $\begin{array}{l}\text { Placebo }(n=10) \\
\text { AST } 6 \mathrm{mg} / \text { day }(\mathrm{n}=10) \\
10 \text { days }\end{array}$ & Blood rheology & Reduced blood transit time & [18] \\
\hline $\begin{array}{l}\text { Randomized, } \\
\text { double-blind, } \\
\text { placebo- } \\
\text { controlled }\end{array}$ & $\begin{array}{l}43 \text { participants with } \\
\text { type } 2 \text { diabetes }(46-62 \\
\text { years) }\end{array}$ & $\begin{array}{l}\text { Placebo }(\mathrm{n}=21) \\
\text { AST } 8 \mathrm{mg} / \text { day }(\mathrm{n}=22) \\
8 \text { weeks }\end{array}$ & $\begin{array}{l}\text { Lipid and glucose } \\
\text { metabolism }\end{array}$ & $\begin{array}{l}\text { Increased adiponectin; } \\
\text { Reduced visceral fat mass, triglycerides, VLDL, } \\
\text { fructosamine, and systolic blood pressure }\end{array}$ & [19] \\
\hline
\end{tabular}

AST = astaxanthin; ${ }^{a}$ individuals without supplementation; ${ }^{\mathrm{b}}$ nonsmoking individuals without supplementation; ${ }^{\mathrm{c}}$ individuals without overweight and without supplementation; $\mathrm{BMI}=$ body mass index; $\mathrm{LDL}=$ low-density lipoprotein; $\mathrm{ApoA} 1=$ apolipoprotein $\mathrm{A} 1 ; \mathrm{ApoB}=$ apolipoprotein $\mathrm{B} ; \mathrm{SOD}=$ superoxide dismutase; $\mathrm{MDA}=$ malondialdehyde; ISP = isoprostane; TAC = total antioxidant capacity; $\mathrm{HDL}=$ high-density lipoprotein; VLDL = very low-density lipoprotein.

15

(1)

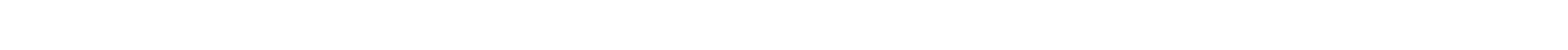

15 


\section{Conclusion}

Based on preclinical and clinical evidence, the antioxidant and anti-inflammatory effects of astaxanthin slow the progression of cardiovascular diseases. As an antioxidant, astaxanthin reduces oxidative stress, increases the bioavailability of $\mathrm{NO}$ and the activity of antioxidant enzymes, and maintains the rheological properties of blood. Its anti-inflammatory properties involve modulating the NF- $\kappa \mathrm{B}$ and MAPK signaling pathways, reducing the release of pro-inflammatory cytokines, and increasing reverse cholesterol transport by HDL, which attenuates the accumulation of cholesterol in foam cells and thus the formation of atherosclerotic plaques. These properties of astaxanthin, together with its demonstrated safety profile, make this compound an important agent in the prevention and/or adjuvant treatment of cardiovascular diseases.

\section{References}

1. World Health Organization. Cardiovascular diseases (CVDs). 2017; World Health Organization:[Available from: https://www.who.int/en/news-room/fact-

sheets/detail/cardiovascular-diseases-(cvds).

2. Spahis, S., J.M. Borys, and E. Levy, Metabolic Syndrome as a Multifaceted Risk Factor for Oxidative Stress. Antioxid Redox Signal, 2017. 26(9): p. 445-461.

3. Vona, R., et al., Biomarkers of Oxidative Stress in Metabolic Syndrome and Associated Diseases. Oxid Med Cell Longev, 2019. 2019: p. 8267234.

4. Puddu, P., et al., Mitochondrial dysfunction as an initiating event in atherogenesis: a plausible hypothesis. Cardiology, 2005. 103(3): p. 137-41.

5. Kishimoto, Y., H. Yoshida, and K. Kondo, Potential Anti-Atherosclerotic Properties of Astaxanthin. Mar Drugs, 2016. 14(2).

6. Guerin, M., M.E. Huntley, and M. Olaizola, Haematococcus astaxanthin: applications for human health and nutrition. Trends Biotechnol, 2003. 21(5): p. 210-6.

7. Hussein, G., et al., Astaxanthin, a carotenoid with potential in human health and nutrition. $\mathrm{J}$ Nat Prod, 2006. 69(3): p. 443-9.

8. Zhang, L. and H. Wang, Multiple Mechanisms of Anti-Cancer Effects Exerted by Astaxanthin. Mar Drugs, 2015. 13(7): p. 4310-30.

9. Maoka, T. and H. Etoh, Some Biological Functions of Carotenoids in Japanese Food, in Functional Foods of the East, J. Shi, C.-T. Ho, and F. Shahidi, Editors. 2010, CRC Press: Boca Raton, FL, USA. p. 85-97.

10. Iwamoto, T., et al., Inhibition of low-density lipoprotein oxidation by astaxanthin. $\mathrm{J}$ Atheroscler Thromb, 2000. 7(4): p. 216-22.

11. Choi, H.D., Y.K. Youn, and W.G. Shin, Positive effects of astaxanthin on lipid profiles and oxidative stress in overweight subjects. Plant Foods Hum Nutr, 2011. 66(4): p. 363-9.

12. Nakagawa, K., et al., Antioxidant effect of astaxanthin on phospholipid peroxidation in human erythrocytes. Br J Nutr, 2011. 105(11): p. 1563-71.

13. Karppi, J., et al., Effects of astaxanthin supplementation on lipid peroxidation. Int J Vitam Nutr Res, 2007. 77(1): p. 3-11.

14. Iwabayashi, M., et al., Efficacy and safety of eight-week treatment with astaxanthin in individuals screened for increased oxidative stress burden. Anti-aging medicine, 2009. 6(4): p. 15-21.

15. Kim, J.H., et al., Protective effects of Haematococcus astaxanthin on oxidative stress in healthy smokers. J Med Food, 2011. 14(11): p. 1469-75.

16. Choi, H.D., et al., Effects of astaxanthin on oxidative stress in overweight and obese adults. Phytother Res, 2011. 25(12): p. 1813-8.

17. Park, J.S., et al., Astaxanthin decreased oxidative stress and inflammation and enhanced immune response in humans. Nutr Metab (Lond), 2010. 7: p. 18. 
18. Miyawaki, H., et al., Effects of astaxanthin on human blood rheology. J Clin Biochem Nutr, 2008. 43(2): p. 69-74.

19. Mashhadi, N.S., et al., Astaxanthin improves glucose metabolism and reduces blood pressure in patients with type 2 diabetes mellitus. Asia Pac J Clin Nutr, 2018. 27(2): p. 341-346.

20. Yoshida, H., et al., Administration of natural astaxanthin increases serum HDL-cholesterol and adiponectin in subjects with mild hyperlipidemia. Atherosclerosis, 2010. 209(2): p. 5203.

21. Lorenz, R.T. and G.R. Cysewski, Commercial potential for Haematococcus microalgae as a natural source of astaxanthin. Trends Biotechnol, 2000. 18(4): p. 160-7.

22. Hulbert, A.J., et al., Life and death: metabolic rate, membrane composition, and life span of animals. Physiol Rev, 2007. 87(4): p. 1175-213.

23. Barros, M.P., et al., Astaxanthin and peridinin inhibit oxidative damage in Fe(2+)-loaded liposomes: scavenging oxyradicals or changing membrane permeability? Biochem Biophys Res Commun, 2001. 288(1): p. 225-32.

24. McNulty, H.P., et al., Differential effects of carotenoids on lipid peroxidation due to membrane interactions: X-ray diffraction analysis. Biochim Biophys Acta, 2007. 1768(1): $\mathrm{p}$. 167-74.

25. Kidd, P., Astaxanthin, cell membrane nutrient with diverse clinical benefits and anti-aging potential. Altern Med Rev, 2011. 16(4): p. 355-64.

26. Donahoe, S.M., et al., Diabetes and mortality following acute coronary syndromes. JAMA, 2007. 298(7): p. 765-75.

27. Cai, H. and D.G. Harrison, Endothelial dysfunction in cardiovascular diseases: the role of oxidant stress. Circ Res, 2000. 87(10): p. 840-4.

28. $\mathrm{Xu}, \mathrm{X}$, et al., Anti-LOX-1 rescues endothelial function in coronary arterioles in atherosclerotic ApoE knockout mice. Arterioscler Thromb Vasc Biol, 2007. 27(4): p. 871-7.

29. Zhao, Z.W., et al., Ameliorative effect of astaxanthin on endothelial dysfunction in streptozotocin-induced diabetes in male rats. Arzneimittelforschung, 2011. 61(4): p. 239-46.

30. da Silva Garrote-Filho, M., M. Bernardino-Neto, and N. Penha-Silva, Influence of Erythrocyte Membrane Stability in Atherosclerosis. Curr Atheroscler Rep, 2017. 19(4): p. 17.

31. Pasterkamp, G. and R. Virmani, The erythrocyte: a new player in atheromatous core formation. Heart, 2002. 88(2): p. 115-6.

32. Hussein, G., et al., Antihypertensive potential and mechanism of action of astaxanthin: II. Vascular reactivity and hemorheology in spontaneously hypertensive rats. Biol Pharm Bull, 2005. 28(6): p. 967-71.

33. Becker, R.C., The role of blood viscosity in the development and progression of coronary artery disease. Cleve Clin J Med, 1993. 60(5): p. 353-8.

34. Hussein, G., et al., Antihypertensive potential and mechanism of action of astaxanthin: III. Antioxidant and histopathological effects in spontaneously hypertensive rats. Biol Pharm Bull, 2006. 29(4): p. 684-8.

35. Monroy-Ruiz, J., et al., Astaxanthin-enriched-diet reduces blood pressure and improves cardiovascular parameters in spontaneously hypertensive rats. Pharmacol Res, 2011. 63(1): p. 44-50.

36. Chen, Y., et al., Astaxanthin Attenuates Hypertensive Vascular Remodeling by Protecting Vascular Smooth Muscle Cells from Oxidative Stress-Induced Mitochondrial Dysfunction. Oxid Med Cell Longev, 2020. 2020: p. 4629189.

37. Sasaki, Y., et al., Astaxanthin inhibits thrombosis in cerebral vessels of stroke-prone spontaneously hypertensive rats. Nutr Res, 2011. 31(10): p. 784-9.

38. Khan, S.K., et al., Novel astaxanthin prodrug (CDX-085) attenuates thrombosis in a mouse model. Thromb Res, 2010. 126(4): p. 299-305.

39. Nordberg, J. and E.S. Arner, Reactive oxygen species, antioxidants, and the mammalian thioredoxin system. Free Radic Biol Med, 2001. 31(11): p. 1287-312.

40. Jekell, A., et al., Elevated circulating levels of thioredoxin and stress in chronic heart failure. Eur J Heart Fail, 2004. 6(7): p. 883-90.

41. Aviram, M., Introduction to the serial review on paraoxonases, oxidative stress, and cardiovascular diseases. Free Radic Biol Med, 2004. 37(9): p. 1301-3. 
42. Augusti, P.R., et al., Astaxanthin prevents changes in the activities of thioredoxin reductase and paraoxonase in hypercholesterolemic rabbits. J Clin Biochem Nutr, 2012. 51(1): p. 42-9.

43. Cui, G., et al., Astaxanthin Protects Ochratoxin A-Induced Oxidative Stress and Apoptosis in the Heart via the Nrf2 Pathway. Oxidative Medicine and Cellular Longevity, 2020.

2020(Article ID 7639109): p. 1-11.

44. Xue, Y., et al., Astaxanthin ameliorates cardiomyocyte apoptosis after coronary microembolization by inhibiting oxidative stress via Nrf2/HO-1 pathway in rats. Naunyn Schmiedebergs Arch Pharmacol, 2019. 392(3): p. 341-348.

45. $\mathrm{Wu}, \mathrm{Q}$., et al., Astaxanthin activates nuclear factor erythroid-related factor 2 and the antioxidant responsive element (Nrf2-ARE) pathway in the brain after subarachnoid hemorrhage in rats and attenuates early brain injury. Mar Drugs, 2014. 12(12): p. 6125-41.

46. Kavitha, K., et al., Chemopreventive effects of diverse dietary phytochemicals against DMBAinduced hamster buccal pouch carcinogenesis via the induction of Nrf2-mediated cytoprotective antioxidant, detoxification, and DNA repair enzymes. Biochimie, 2013. 95(8): p. 1629-39.

47. Tripathi, D.N. and G.B. Jena, Astaxanthin intervention ameliorates cyclophosphamideinduced oxidative stress, DNA damage and early hepatocarcinogenesis in rat: role of Nrf2, p53, p38 and phase-II enzymes. Mutat Res, 2010. 696(1): p. 69-80.

48. Saw, C.L., et al., Astaxanthin and omega-3 fatty acids individually and in combination protect against oxidative stress via the Nrf2-ARE pathway. Food Chem Toxicol, 2013. 62: p. 869-75.

49. Wen, X., et al., Neuroprotective effect of astaxanthin against glutamate-induced cytotoxicity in HT22 cells: Involvement of the Akt/GSK-3beta pathway. Neuroscience, 2015. 303: p. 55868.

50. Visioli, F. and C. Artaria, Astaxanthin in cardiovascular health and disease: mechanisms of action, therapeutic merits, and knowledge gaps. Food Funct, 2017. 8(1): p. 39-63.

51. Li, J., et al., Astaxanthin Inhibits Proliferation and Induces Apoptosis of Human Hepatocellular Carcinoma Cells via Inhibition of Nf-Kappab P65 and Wnt/Beta-Catenin in Vitro. Mar Drugs, 2015. 13(10): p. 6064-81.

52. Kochi, T., et al., Inhibitory effects of astaxanthin on azoxymethane-induced colonic preneoplastic lesions in C57/BL/KsJ-db/db mice. BMC Gastroenterol, 2014. 14: p. 212.

53. Kavitha, K., et al., Astaxanthin inhibits NF-kappaB and Wnt/beta-catenin signaling pathways via inactivation of Erk/MAPK and PI3K/Akt to induce intrinsic apoptosis in a hamster model of oral cancer. Biochim Biophys Acta, 2013. 1830(10): p. 4433-44.

54. Yasui, Y., et al., Dietary astaxanthin inhibits colitis and colitis-associated colon carcinogenesis in mice via modulation of the inflammatory cytokines. Chem Biol Interact, 2011. 193(1): p. 79-87.

55. Nagendraprabhu, P. and G. Sudhandiran, Astaxanthin inhibits tumor invasion by decreasing extracellular matrix production and induces apoptosis in experimental rat colon carcinogenesis by modulating the expressions of ERK-2, NFkB and COX-2. Invest New Drugs, 2011. 29(2): p. 207-24.

56. Moroni, F., et al., The Role of Monocytes and Macrophages in Human Atherosclerosis, Plaque Neoangiogenesis, and Atherothrombosis. Mediators Inflamm, 2019. 2019: p. 7434376.

57. Hashizume, M. and M. Mihara, Blockade of IL-6 and TNF-alpha inhibited oxLDL-induced production of MCP-1 via scavenger receptor induction. Eur J Pharmacol, 2012. 689(1-3): p. 249-54.

58. Zou, T.B., et al., Effects of Astaxanthin on Reverse Cholesterol Transport and Atherosclerosis in Mice. Biomed Res Int, 2017. 2017: p. 4625932.

59. Kishimoto, Y., et al., Astaxanthin suppresses scavenger receptor expression and matrix metalloproteinase activity in macrophages. Eur J Nutr, 2010. 49(2): p. 119-26.

60. Santos, S.D., et al., Shrimp waste extract and astaxanthin: rat alveolar macrophage, oxidative stress and inflammation. J Food Sci, 2012. 77(7): p. H141-6. 
61. Lee, S.J., et al., Astaxanthin inhibits nitric oxide production and inflammatory gene expression by suppressing I(kappa)B kinase-dependent NF-kappaB activation. Mol Cells, 2003. 16(1): p. 97-105.

62. Franceschelli, S., et al., Astaxanthin treatment confers protection against oxidative stress in U937 cells stimulated with lipopolysaccharide reducing O2-production. PLoS One, 2014. 9(2): p. e88359.

63. Macedo, R.C., et al., Astaxanthin addition improves human neutrophils function: in vitro study. Eur J Nutr, 2010. 49(8): p. 447-57.

64. Choi, S.K., et al., Effects of astaxanthin on the production of NO and the expression of COX-2 and iNOS in LPS-stimulated BV2 microglial cells. J Microbiol Biotechnol, 2008. 18(12): p. 1990-6.

65. Kim, Y.J., Y.A. Kim, and T. Yokozawa, Protection against oxidative stress, inflammation, and apoptosis of high-glucose-exposed proximal tubular epithelial cells by astaxanthin. $\mathrm{J}$ Agric Food Chem, 2009. 57(19): p. 8793-7.

66. Abdelzaher, L.A., et al., Astaxanthin alleviates oxidative stress insults-related derangements in human vascular endothelial cells exposed to glucose fluctuations. Life Sci, 2016. 150: p. 24-31.

67. Speranza, L., et al., Astaxanthin treatment reduced oxidative induced pro-inflammatory cytokines secretion in U937: SHP-1 as a novel biological target. Mar Drugs, 2012. 10(4): p. 890-9.

68. Jones, W.K., et al., NF-kappaB in cardiovascular disease: diverse and specific effects of a "general" transcription factor? Cardiovasc Toxicol, 2005. 5(2): p. 183-202.

69. Pashkow, F.J., D.G. Watumull, and C.L. Campbell, Astaxanthin: a novel potential treatment for oxidative stress and inflammation in cardiovascular disease. Am J Cardiol, 2008.

101(10A): p. 58D-68D.

70. Ghosh, S., M.J. May, and E.B. Kopp, NF-kappa B and Rel proteins: evolutionarily conserved mediators of immune responses. Annu Rev Immunol, 1998. 16: p. 225-60.

71. Woronicz, J.D., et al., IkappaB kinase-beta: NF-kappaB activation and complex formation with IkappaB kinase-alpha and NIK. Science, 1997. 278(5339): p. 866-9.

72. Mercurio, F., et al., IKK-1 and IKK-2: cytokine-activated IkappaB kinases essential for NFkappaB activation. Science, 1997. 278(5339): p. 860-6.

73. Zandi, E., et al., The IkappaB kinase complex (IKK) contains two kinase subunits, IKKalpha and IKKbeta, necessary for IkappaB phosphorylation and NF-kappaB activation. Cell, 1997. 91(2): p. 243-52.

74. DiDonato, J.A., et al., A cytokine-responsive IkappaB kinase that activates the transcription factor NF-kappaB. Nature, 1997. 388(6642): p. 548-54.

75. Ghosh, S. and M. Karin, Missing pieces in the NF-kappaB puzzle. Cell, 2002. 109 Suppl: p. S81-96.

76. Wang, H.H., et al., Cholesterol and Lipoprotein Metabolism and Atherosclerosis: Recent Advances in Reverse Cholesterol Transport. Ann Hepatol, 2017. 16 Suppl 1: p. S27-S42.

77. Khera, A.V. and D.J. Rader, Future therapeutic directions in reverse cholesterol transport. Curr Atheroscler Rep, 2010. 12(1): p. 73-81.

78. Tall, A.R. and L. Yvan-Charvet, Cholesterol, inflammation and innate immunity. Nat Rev Immunol, 2015. 15(2): p. 104-16.

79. Shao, B., et al., Humans with atherosclerosis have impaired ABCA1 cholesterol efflux and enhanced high-density lipoprotein oxidation by myeloperoxidase. Circ Res, 2014. 114(11): p. 1733-42.

80. Clarke, M.C. and M.R. Bennett, Cause or consequence: what does macrophage apoptosis do in atherosclerosis? Arterioscler Thromb Vasc Biol, 2009. 29(2): p. 153-5.

81. Kalogeris, T., et al., Cell biology of ischemia/reperfusion injury. Int Rev Cell Mol Biol, 2012. 298: p. 229-317.

82. Sanderson, T.H., et al., Molecular mechanisms of ischemia-reperfusion injury in brain: pivotal role of the mitochondrial membrane potential in reactive oxygen species generation. Mol Neurobiol, 2013. 47(1): p. 9-23. 
83. Curek, G.D., et al., Effect of astaxanthin on hepatocellular injury following ischemia/reperfusion. Toxicology, 2010. 267(1-3): p. 147-53.

84. Li, J., et al., Astaxanthin Pretreatment Attenuates Hepatic Ischemia Reperfusion-Induced Apoptosis and Autophagy via the ROS/MAPK Pathway in Mice. Mar Drugs, 2015. 13(6): p. 3368-87.

85. Cai, X., et al., Astaxanthin prevents against lipopolysaccharide-induced acute lung injury and sepsis via inhibiting activation of $M A P K / N F-k a p p a B$. Am J Transl Res, 2019. 11(3): p. 18841894.

86. Lauver, D.A., S.F. Lockwood, and B.R. Lucchesi, Disodium Disuccinate Astaxanthin (Cardax) attenuates complement activation and reduces myocardial injury following ischemia/reperfusion. J Pharmacol Exp Ther, 2005. 314(2): p. 686-92.

87. Ni, Y., et al., Astaxanthin prevents and reverses diet-induced insulin resistance and steatohepatitis in mice: A comparison with vitamin E. Sci Rep, 2015. 5: p. 17192. 